(c) American Dairy Science Association, 2006.

\title{
Pre-Conception Energy Balance and Secondary Sex Ratio-Partial Support for the Trivers-Willard Hypothesis in Dairy Cows
}

\author{
J. R. Roche, ${ }^{\star 1}$ J. M. Lee, ${ }^{*}$ and D. P. Berry† \\ *Dexcel, Hamilton, New Zealand \\ †Teagasc Moorepark, Fermoy, Co. Cork, Ireland
}

\begin{abstract}
According to the Trivers-Willard hypothesis, maternal condition at or around conception affects the secondary sex ratio in mammals. However, there are little or no data available on indicators of maternal condition in dairy cows on the sex of the resultant offspring. A total of 76,607 body condition score (BCS; scale of 1 to 5) records and 76,611 body weight (BW) records from 3,209 lactations across 1,172 cows were extracted from a research database collated from one research herd between 1986 and 2004, inclusive. Exclusion of multiple births and cows with no information before calving (e.g., nulliparous animals) resulted in 2,029 records with $\mathrm{BCS}$ and $\mathrm{BW}$ observations from the previous calving, and 2,002 and 1,872 lactations with BCS and BW observations at conception and midgestation, respectively. Change in BCS and BW between calving and conception and between conception and midgestation was calculated per lactation. Generalized estimating equations were used to model the logit of the probability of a male calf, in which cow was included as a repeated effect with a first-order autoregressive correlation structure assumed among records within cow. Of the BCS variables investigated, there was a linear relationship between the logit of the probability of a male calf and BCS change between calving and conception, the rate of BCS change over this period (BCS divided by days in milk), and BCS at the calving event immediately before conception. The birth of a bull calf was 1.85 times more likely in cows that lost no BCS from calving to conception compared with cows that lost one BCS unit from calving to conception. This increase in odds was equivalent to a $14 \%$ unit increase in the probability of a male calf (from 54 to 68\%). The amount of BW lost between calving and conception and the rate of loss affected the sex of the resultant offspring. Less BW loss or greater BW gain between calving and conception was associated with greater likelihood of a male calf. Results
\end{abstract}

Received October 17, 2005.

Accepted January 4, 2006.

${ }^{1}$ Corresponding author: john.roche@dexcel.co.nz suggested a positive effect of pre-conception BCS and BW change on secondary sex ratio, agreeing with the Trivers-Willard hypothesis that females in good physiological condition are more likely to produce male offspring.

Key words: sex ratio, body condition score, TriversWillard, maternal condition

\section{INTRODUCTION}

Fisher's (1930) theory dictated that maternal investment in male and female offspring is similar, and that secondary sex ratio (SSR; the proportion of males to females at birth) should be 50:50 if one sex does not require greater maternal investment than the other. Nevertheless, there is compelling evidence to conclude that, under certain conditions, natural selection favors systematic deviations from this expected 50:50 sex ratio. For example, the SSR is reported to be $52: 48$ in dairy cattle (Skjervold and James, 1979). Furthermore, factors as diverse as latitude of residence (Grech et al., 2000), ethnicity (Lyster, 1972), dominant weather patterns (Lerchl, 1998), timing and frequency of coitus relative to ovulation (James, 1997), diet (Lyster, 1972; Stolkowski and Choukroun, 1981), paternal age (Jacobsen et al., 1999) and alcohol consumption (Chaudhuri, 1928), parental age gap (Manning et al., 1997), maternal blood type (Allan, 1975), BCS (Cameron, 2004), vaginal $\mathrm{pH}$ (Pratt et al., 1987), and the systemizing and empathizing skills of the dam (Grant, 2003) have all been statistically associated with altered SSR in mammals.

Trivers and Willard (1973) hypothesized that in species in which reproductive success varies more among one sex than the other, mothers in better physiological condition would be advantaged by investing more heavily in the more variable sex. Similarly, mothers with limited resources would be advantaged by investing in the more reproductively stable sex, thereby ensuring a continuation of the genetic line. This hypothesis is appropriate for species with a small litter size and depends on 3 premises (Trivers and Willard, 1973; Cameron et al., 1999): 1) that the condition of the young at the end of the parental investment is correlated with 
the condition of the dam during parental investment; 2 ) that these differences in condition tend to endure into adulthood; and 3) that the adult will be differentially advantaged in reproductive success through slight advantages in condition. This model predicts that dairy cows in good physiological condition are more likely to produce male offspring, because the theory suggests that a male in good condition at the end of the period of parental investment is expected to out-reproduce female siblings.

The hypothesis has been tested more than 1,000 times since it was proposed, but results have been inconsistent. In a review of the literature, Cameron (2004) reported significant support for the hypothesis in only $34 \%$ of cases tested, with $8.5 \%$ of studies showing results contrary to the hypothesis (i.e., dams in poorer condition produced more male offspring). However, Cameron (2004) further concluded that much of this inconsistency was a result of different definitions of "maternal condition," and that when studies testing maternal BCS were isolated, support for the hypothesis increased to $74 \%$.

Maternal skewing of SSR may have important implications for dairying, with heifers generally of greater value than bulls. The objective of the current study was to determine if dairy cows conformed to the TriversWillard (TW) hypothesis, and to determine the effect, if any, of maternal BCS at conception and BCS change pre- and postconception on the sex of the resultant calf.

\section{MATERIALS AND METHODS}

\section{Data}

Data used in the present study were extracted from a database collated from No. 2 Dairy, Dexcel (Hamilton, New Zealand) between 1986 and 2004. No. 2 Dairy farm was used for systems-based research, and the period in question incorporated research comparing the profitability of Holstein-Friesian and Jersey heifers under grazing systems, different pasture species and cultivars, different grazing rotation lengths, systems that optimized use of nitrogen fertilizer and supplementary feeds, and research to determine the most profitable stocking rate for grazing dairy systems (Macdonald, 1997).

The system of milk production was seasonal, with approximately $50 \%$ of cows calving in 2 wk, $40 \%$ calving in the next $4 \mathrm{wk}$, and the remaining cows calving during wk 7 and 8. Any cows whose planned calving date was later than wk 8 were hormonally induced to calve during wk 7 and 8 using a 2-step combination of dexamethasone (Opticortenol S, Novartis Animal Health, Switzerland; Voren, Boehringer-Ingelheim, UK) and prostaglandin (Estrumate, Schering-Plough Coopers, New
Zealand), provided they had low SCC, were in a BCS of 3.0 or greater, and blood metabolites did not indicate health concerns.

A total of 76,607 BCS records and 76,611 BW records, from 3,209 lactations across 1,172 cows were extracted from the database. Body condition score was assessed pre- and postcalving on a 10 -point scale $(1=$ emaciated and 10 = obese; Macdonald and Roche, 2004). Body condition score is a subjective measure of subcutaneous fat reserves, measured through palpating key areas of the cow's anatomy. The anatomical regions considered most important include the thoracic and vertebral region of the spinal column (chine, loin, and rump), the ribs, the spinous processes (loin), the tuber sacrale (hip or hook bones), the tuber ischii (pin bones), the anterior coccygeal vertebrae (tail head), and the thigh region (Roche et al., 2004). These scores were then converted to the 5-point scale of Wildman et al. (1982) using the regression equation generated by Roche et al. (2004; 5point BCS $=1.5+0.32 \times 10$-point BCS).

Data on calving dates and sex of the calf born were available for 3,171 of these lactations. Multiple births ( $\mathrm{n}=59$ ) were removed from the analysis. There were 1,152 records for first-calving cows, or cows that entered the herd at a higher parity with no BCS or BW record from the previous calving/breeding period. Based on the date of calving, the expected date of conception was derived by subtracting the expected gestation length (282 d; Macmillan and Curnow, 1976) from the recorded calving date. Date at midgestation was also derived by subtracting $141 \mathrm{~d}$ from calving date. Body condition score and BW at conception were calculated by identifying the record nearest to the calculated date of conception. Retained BCS and BW records were restricted to be within $7 \mathrm{~d}$ of the calculated date of conception/ midgestation. Where 2 records were available equidistant from these dates, data before the date of conception were retained. An identical technique was used to extract $\mathrm{BCS}$ and $\mathrm{BW}$ at midgestation. Body condition score and BW at calving was the first record taken within $7 \mathrm{~d}$ after calving. Average lactation BCS and $\mathrm{BW}$ were calculated as the average of all BCS and BW records within lactations that had over 10 observations with at least one observation before $10 \mathrm{~d}$ postcalving and at least one observation after $100 \mathrm{~d}$ postcalving.

Following the criteria enforced, 2,029 BCS and BW records from the previous calving were available for inclusion in the analysis, and 2,002 and 1,872 records at conception and midgestation, respectively, were available. Change in BCS and BW between calving and conception and between conception and midgestation were calculated per cow-parity where an animal had a record for each of the 2 variables in the respective 
calculation. Body weight of the subsequent calf at birth was available on 2,022 calves.

To test the influence of factors other than BCS- or BW-related variables on SSR, 2,835 lactations with information on ancillary traits (e.g., year, parity, week of conception) were included in the analysis; these lactation records were not required to have information on BCS- or BW-related variables. In the current analysis, year was defined as the year in which pregnancy occurred. Similarly, parity was defined as the parity (coded as zero for nulliparous animals) when conception occurred. Sex of the previous calf born to each cow was retained for inclusion in the analysis where a separate code was allocated to nulliparous animals and animals where no previous data were available. Week of the year at conception was also derived.

\section{Statistical Analyses}

Generalized estimating equations were used because of the binary nature of SSR and the repeated records per cow within the current data set. The logit of the probability of a male calf was modeled using PROC GENMOD (SAS Institute, 2005) with cow included as a repeated effect with a first-order autoregressive correlation structure assumed among records within cow. Empirical standard errors of the model solutions are reported herein. Factors tested in the model of analysis were year of conception, parity of the cow at conception, week of the year at conception, sex of the immediately previous calf within cow, and the various BCS and BW variables. The generalized estimating equations score was used to test the significance of each effect in the model based on a univariate analysis.

The probability of a male calf being born was estimated using the results from the analyses as

$$
P(\mathrm{X})=\left(1+e^{-(\hat{\alpha}+\hat{\beta} \mathrm{X})}\right)^{-1}
$$

where $\hat{\alpha}$ is the predicted intercept of the model, and $\hat{\beta}$ is the predicted regression coefficient for independent variable $X$. Odds ratios were calculated as the exponent of the model solutions. However, because of the proportionally relatively small incremental measurement of BW-related variables (i.e., kilograms), the odds ratios and associated confidence intervals for BW-related variables were standardized and are expressed per SD change.

An odds ratio compares opposing probabilities to determine which is the more likely result for a given outcome; in this instance the outcome was the probability of a male calf. In the present study, if the odds ratio is 1.5, then animals exhibiting the level of the independent variable under investigation have a $50 \%$ greater likelihood of having a male calf. An odds ratio of 2 reflects double the likelihood of a male calf.

Partial correlations between the various BCS- and BW-related variables and subsequent calf birth weight were estimated using PROC CORR (SAS Institute, 2005). Birth weight of the calf was adjusted for the sex of the calf using PROC GLM (SAS Institute, 2005), and the partial correlations of the resultant residuals and the BCS- and BW-related variables estimated.

\section{RESULTS}

The distribution of days in milk at conception is illustrated in Figure 1. On average, cows achieved a successful pregnancy $87 \pm 21 \mathrm{~d}$ postcalving (mean $\pm \mathrm{SD}$ ). Neither year of conception, week of the year at conception, parity, or previous calf sex significantly affected SSR. The proportion of male calves born averaged 0.52 across the entire data set.

The effect of BCS and BW states and changes in BCS and BW states on the odds of a male calf being born are presented in Table 1. Of the BCS variables investigated, BCS at calving, the BCS change between calving and conception, and the rate of BCS change postcalving (i.e., BCS change divided by DIM from calving to conception) affected $(P<0.05)$ the SSR. The odds of a male calf increased in cows that were thinner at calving, cows that lost least BCS (or gained most BCS) between calving and conception, or cows that lost BCS at a slower rate (or gained BCS at a faster rate) between calving and conception. Cow BCS at conception or midgestation, average BCS in the lactation in which conception occurred, and BCS change from conception to midgestation did not significantly affect SSR.

The odds of a male calf were 0.57 that of a female calf when cows were 1 BCS unit higher at the calving event immediately preceding breeding. This equates to a 7-percentage unit greater probability of a bull calf being born to a dam calving at 2.5 BCS units compared with a dam calving at the sample population mean of 3.0 BCS units. The odds of the birth of a bull calf were 1.85 times that of a female calf when BCS change from calving to conception was more positive by 1 BCS unit. This is equivalent to a 14-percentage unit decrease in SSR when BCS loss between calving and conception increased by 1 BCS unit.

The SD of BW at calving, conception, midgestation, and on average across lactation was $70.7,63.6,58.8$, and $62.1 \mathrm{~kg}$, respectively. The SD of BW change between calving and conception and between conception and gestation was 38.1 and $25.2 \mathrm{~kg}$, respectively, and the SD of the daily rate of BW change was $0.52 \mathrm{~kg} / \mathrm{d}$. The effect of BW on SSR was similar to the effect of BCS on SSR. There was an increased probability of a bull calf being 


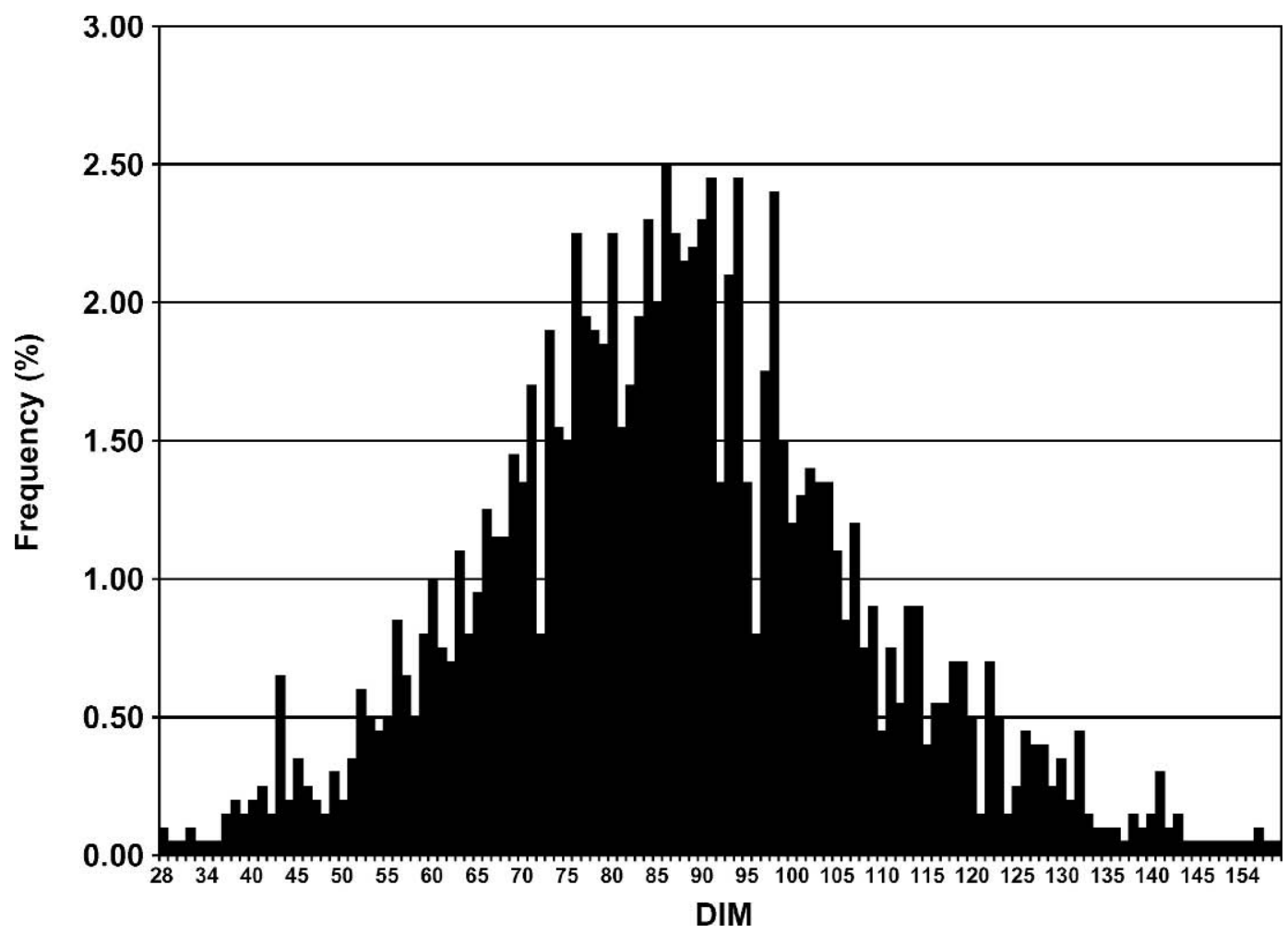

Figure 1. Distribution of DIM at conception.

born when the amount and rate of BW loss between calving and conception were lower, or when BW gain was greater. No other BW variable significantly affected the SSR. Greater BW gain between calving and conception was associated with greater likelihood of a male calf (standardized odds ratio $=1.10$ ). Thus, cows that either lost $1 \mathrm{SD}$ (i.e., $38.1 \mathrm{~kg}$ ) less or gained $1 \mathrm{SD}$ more BW between calving and conception were $10 \%$ more likely to give birth to a male calf subsequently.

The mean for each of the BCS and BW variables investigated in which the resultant calf was male or female is summarized in Table 2. Body condition score

Table 1. The intercept, odds ratio, associated 95\% confidence intervals (CI), and the significance of the different BCS and BW variables when modeling the probability of a male calf

\begin{tabular}{lclll}
\hline Variable $^{1}$ & Intercept & $\begin{array}{l}\text { Odds } \\
\text { ratio }\end{array}$ & $95 \%$ CI & $P$-value \\
\hline BCS at calving & 1.765 & 0.57 & $0.374-0.883$ & $<0.01$ \\
BCS at conception & -0.436 & 1.19 & $0.737-1.935$ & $\mathrm{NS}$ \\
BCS at midgestation & -0.136 & 1.08 & $0.677-1.716$ & $\mathrm{NS}$ \\
BCS change from calving to conception & 0.160 & 1.85 & $1.219-2.799$ & $<0.005$ \\
BCS change from conception to midgestation & 0.064 & 0.97 & $0.584-1.625$ & $\mathrm{NS}$ \\
Rate of BCS change (BCS units $\left.\times 10^{-3} / \mathrm{d}\right)$ & 1.67 & 1.67 & $1.234-2.262$ & $<0.001$ \\
Average BCS & 0.260 & 0.94 & $0.515-1.720$ & $\mathrm{NS}$ \\
BW at calving & 0.218 & 0.98 & $0.900-1.071$ & $\mathrm{NS}$ \\
BW at conception & -0.147 & 1.03 & $0.948-1.130$ & $\mathrm{NS}$ \\
BW at midgestation & -0.332 & 1.06 & $0.965-1.157$ & $\mathrm{NS}$ \\
BW change from calving to conception & 0.136 & 1.10 & $1.003-1.197$ & $<0.05$ \\
BW change from conception to midgestation & 0.043 & 1.03 & $0.940-1.129$ & $\mathrm{NS}$ \\
Rate of BW change $(\mathrm{kg} / \mathrm{d})$ & 0.137 & 1.10 & $1.009-1.204$ & $<0.05$ \\
Average BW & -0.185 & 1.04 & $0.953-1.135$ & $\mathrm{NS}$ \\
\hline
\end{tabular}

${ }^{1}$ BCS-related variables are measured in BCS units ( 1 to 5 , where 1 is emaciated and 5 is obese) unless otherwise stated, whereas BW-related variables are measured in kilograms but are expressed as standardized values. 
Table 2. Raw means for the different BCS and BW variables when the subsequent calf is either male or female

\begin{tabular}{|c|c|c|c|}
\hline Variable $^{1}$ & Male & Female & $\mathrm{SED}^{2}$ \\
\hline BCS at calving & 3.02 & 3.05 & 0.009 \\
\hline BCS at conception & 2.90 & 2.89 & 0.008 \\
\hline $\mathrm{BCS}$ at midgestation & 2.84 & 2.83 & 0.010 \\
\hline BCS change from calving to conception & -0.127 & -0.156 & 0.010 \\
\hline BCS change from conception to midgestation & -0.063 & -0.062 & 0.008 \\
\hline Rate of BCS change ${ }^{3}\left(\right.$ BCS units $\left.\times 10^{-3} / \mathrm{d}\right)$ & -1.63 & -2.07 & 0.131 \\
\hline Average BCS & 2.91 & 2.91 & 0.007 \\
\hline BW at calving & 447 & 449 & 3.2 \\
\hline BW at conception & 424 & 421 & 2.9 \\
\hline BW at midgestation & 449 & 446 & 2.7 \\
\hline BW change from calving to conception & -24 & -27 & 1.7 \\
\hline BW change from conception to midgestation & 22 & 21 & 1.2 \\
\hline Rate of BW change ${ }^{3}(\mathrm{~kg} / \mathrm{d})$ & -0.31 & -0.36 & 0.023 \\
\hline Average BW & 444 & 441 & 2.8 \\
\hline
\end{tabular}

${ }^{1}$ BCS-related variables are measured in BCS units ( 1 to 5 , where 1 is emaciated and 5 is obese) unless otherwise stated, whereas BW-related variables are measured in kilograms but are expressed as standardized values.

${ }^{2}$ Standard error of the difference.

${ }^{3}$ Between calving and conception.

at the calving preceding the relevant conception was, on average, $0.03 \mathrm{BCS}$ units lower when the subsequently conceived calf was male. Likewise, a loss of 0.03 BCS units less, on average, between calving and conception was associated with the conception and subsequent birth of a male calf. Similarly, lactations in which less BW was lost between calving and conception were associated with a bull calf being born subsequently.

The correlations between BCS- and BW-related attributes of the dam and the birth weight of the subsequent calf are summarized in Table 3. Body condition score of the cow at the calving event immediately before conception was negatively correlated with subsequent calf birth weight. Although BCS at conception was not significantly correlated with calf birth weight, the amount and rate of change in BCS between calving and conception was positively correlated with subsequent calf birth weight. On average, cows that lost more BCS between calving and conception or lost BCS at a greater rate had lighter calves subsequently. Adjustment of calf birth weight for calf sex had a minimal effect on the correlations. The least squares means for calf birth weight was 38 and $35 \mathrm{~kg}$ (SED = $0.3 \mathrm{~kg}$ ) for male and female calves, respectively. All of the BW variables measured on the dam, with the exception of the amount and rate of $\mathrm{BW}$ change from calving to conception, were associated $(P<0.05)$ with birth weight of the calf.

\section{DISCUSSION}

Average SSR (52\% males) was similar to previously reported values in dairy cattle (Skjervold and James, 1979). Maternal BCS or BW at conception or midgestation did not affect SSR, but there was a negative relationship between the BCS and BW change between calving and conception and SSR (i.e., the lower the loss, the greater the likelihood of a bull being born in the

Table 3. Correlation coefficients between cow BCS and BW, and subsequent calf birth weight (either unadjusted or adjusted for calf sex)

\begin{tabular}{lllllc}
\hline & \multicolumn{2}{c}{ Unadjusted } & & \multicolumn{2}{c}{ Adjusted } \\
\cline { 2 - 3 } \cline { 5 - 6 } Variable & BCS & BW & & BCS & BW \\
\hline Calving & $-0.06^{* * *}$ & $0.37^{* * *}$ & & $-0.05^{* *}$ & $0.37^{* * * *}$ \\
Conception & 0.03 & $0.40^{* * *}$ & & 0.03 & $0.40^{* * *}$ \\
Midgestation & 0.04 & $0.43^{* * *}$ & & 0.04 & $0.44^{* * * *}$ \\
Change from calving to conception & $0.09^{* * *}$ & -0.01 & & $0.07^{* * *}$ & -0.02 \\
Change from conception to midgestation $^{\text {Rate of change }}{ }^{1}$ & 0.03 & $0.09^{* * *}$ & & 0.03 & $0.08^{* * * *}$ \\
Average & $0.09^{* * *}$ & -0.01 & & $0.07^{* * *}$ & -0.02 \\
\hline
\end{tabular}

${ }^{1}$ Between calving and conception.

*** $P<0.001 ; * * P<0.01 ; * P<0.05$. 
following calving), supporting the TW hypothesis that dams in better condition give birth to more males.

Secondary sex ratio was also negatively associated with BCS at calving and the rate of change in BCS and BW between calving and conception. This relationship is probably a result of the strong correlation between BCS change from calving to conception and the rate of change in BCS between calving and conception and BCS at calving. Correlations estimated from the present data set were all stronger than -0.60 . Berry et al. (2002) reported a similar correlation $(-0.68)$ between BCS $5 \mathrm{~d}$ postpartum and BCS change in the first $60 \mathrm{~d}$ of lactation. The similarity in the trait definitions of BCS and BW that significantly affected SSR may also be partly attributed to the correlation between BCS and BW loss from calving to conception (0.50). The strength of this correlation is consistent with that reported by Berry et al. $(2002 ; \mathrm{r}=0.44)$ between BCS and BW loss in the first $60 \mathrm{~d}$ of lactation, and indicates that BW in this study explains approximately $25 \%$ of the variation in BCS, and vice versa.

Although Fisher's (1930) theory suggested that the probability of a male or female calf should be equal (50\%) in situations of evolutionary equilibrium, natural selection should favor the parental ability to adjust offspring sex ratio according to any advantage accorded the individual by the gender outcome of the breeding event (Trivers and Willard, 1973). In most mammals, including cattle, males benefit more than females from increased maternal investment, because body size is an important determinant of reproductive success in males but less so in females. Consequently, any situation that results in increased offspring size should favor the birth of male offspring, because a male would be expected to out-reproduce a female counterpart. The corollary also holds true; as offspring size declines, the resultant SSR will be biased toward females because a size-disadvantaged female will breed, but a size-disadvantaged male will be unable to compete with stronger males in his cohort. This is the basis for the TW hypothesis and is, at least in part, consistent with results presented in the current study, in which physical attributes of the dam that resulted in larger calves following adjustment for calf sex resulted in a greater proportion of bull calves being born.

Although Trivers and Willard (1973) hypothesized that increased maternal condition tends to result in a greater SSR in species in which there is gender-dependent variability in reproductive success, they failed to clearly define "maternal condition". A recent comprehensive review by Cameron (2004; 381 studies) reported significant support for the hypothesis in only $34 \%$ of cases tested, with $8.5 \%$ of studies showing results contrary to the hypothesis (i.e., dams in poorer condition produced more male offspring). However, this is probably because of a lack of consistency in the measure of condition being tested (e.g., dam age, population density, food supply, maternal dominance, parity). Cameron (2004) found significant support for the TW hypothesis when maternal condition was defined as BCS (25 studies; $74 \%$ support), and particularly when BCS was measured close to conception (92\% of studies). Sheldon and West (2004) confirmed these findings in ungulate mammals, suggesting that the theory may hold true for periconception BCS measures in dairy cows. Results presented here confirm a relationship between BCS and SSR, but, unlike the results of Cameron (2004) and Sheldon and West (2004), BCS at conception did not affect SSR in the present study. Instead, BCS change between calving and conception and the rate of change between calving and conception were the dominant measures of maternal condition influencing SSR.

Although apparently contradictory to the previous studies reviewed by Cameron (2004), it is conceivable that the results are compatible and that the discrepancy is due to a lack of sufficient measurements in those studies. From her meta-analysis, Cameron (2004) concluded that maternal BCS at or around conception was the most influential BCS measure on subsequent SSR. However, it is not possible to determine the premating trend in BCS change from that analysis. It is plausible that dams in lower BCS at conception (i.e., producing a lower SSR in her review) were either losing BCS or gaining less BCS before conception, a factor shown to reduce the SSR in the study reported here. Similarly, dams in good condition at conception in Cameron's (2004) review may have been losing less or gaining more condition before conception, resulting in greater male births subsequently. Nevertheless, the results presented here suggest a positive relationship between preconception BCS change and SSR.

There is physiological support for an effect of BCS on SSR presented here. Firstly, there is sexual dimorphism in embryo metabolic rate (Ray et al., 1995; Dumoulin et al., 2005) and in the expression of IFN- $\tau$ (Kimura et al., 2004), suggesting sex-differential signaling of the dam by the embryo; this provides a potential mechanism for active sex selection. Secondly, there is in vitro evidence that the glucose content of the blastocyst growth medium skews survival in favor of males, suggesting a potential effect of blood glucose on SSR (Larson et al., 2001). Cameron (2004) provided substantial evidence for a positive effect of plasma glucose and factors favoring increased plasma glucose on SSR. This is consistent with reduced SSR in humans with declining caloric availability (Williams and Gloster, 1992).

This positive effect of plasma glucose on survival of the male blastocyst is consistent with the effect of pre- 
conception BCS change on SSR. Both Reist et al. (2002) and Roche et al. (2005) reported a linear reduction in plasma glucose concentration in cows with declining energy balance, and a simultaneous increase in BCS mobilization. In comparison, there is no evidence to suggest that cows in different BCS states will have different plasma glucose concentrations, supporting the lack of effect of BCS at conception on SSR in the current study. In conclusion, there is evidence for a periconception adjustment in SSR in dairy cattle, indicating a greater proportion of bull calves when the rate of BCS change and the amount of BCS change between calving and conception becomes more positive, and a greater proportion of heifers when the opposite occurs.

\section{ACKNOWLEDGMENTS}

The authors wish to acknowledge the assistance of $\mathrm{K}$. Macdonald and J. Lancaster in compiling the database.

\section{REFERENCES}

Allan, T. M. 1975. ABO blood groups and human sex ratio at birth. J. Reprod. Fertil. 43:209-219.

Berry, D. P., F. Buckley, P. Dillon, R. D. Evans, M. Rath, and R. F. Veerkamp. 2002. Genetic parameters for level and change of body condition score and body weight in dairy cows. J. Dairy Sci. 85:2030-2039.

Cameron, E. Z. 2004. Facultative adjustment of mammalian sex ratios in support of the Trivers-Willard hypothesis: Evidence for a mechanism. Proc. R. Soc. Lond., B, Biol. Sci. 271:1723-1728.

Cameron, E. Z., W. L. Linklater, K. J. Stafford, and C. J. Veltman. 1999. Birth sex ratios relate to mare condition at conception in Kaimanawa horses. Behav. Ecol. 10:472-475.

Chaudhuri, A. C. 1928. The effect of the injection of alcohol into the male mouse upon the secondary sex ratio among the offspring. Br. J. Exp. Biol. 5:185-186.

Dumoulin, J. C. M., J. G. Derhaag, M. Bras, A. P. A. Van Montfoort, A. D. M. Kester, J. L. H. Evers, J. P. M. Geraedts, and E. Coonen. 2005. Growth rate of human preimplantation embryos is sex dependent after ICSI but not after IVF. Hum. Reprod. 20:484-491.

Fisher, R. A. 1930. The Genetical Theory of Natural Selection. Oxford University Press, Oxford, UK.

Grant, V. J. 2003. The maternal dominance hypothesis. Questioning Trivers and Willard. Evol. Psychol. 1:96-107.

Grech, V., P. Vassalos-Agios, and C. Savona-Ventura. 2000. Declining male births with increasing geographical latitude in Europe. J. Epidemiol. Community Health 54:244-266.

Jacobsen, R., H. Moller, and A. Mouritsen. 1999. Natural variation in the human sex ratio. Hum. Reprod. 14:3120-3125.

James, W. H. 1997. Sex ratio, coital rate, hormones and time of fertilization within the cycle. Ann. Hum. Biol. 24:403-409.
Kimura, K., L. D. Spate, M. P. Green, C. N. Murphy, G. E. Seidel, Jr., and R. M. Roberts. 2004. Sexual dimorphism in interferon-tau by in vivo derived bovine embryos. Mol. Reprod. Dev. 67:193-199.

Larson, M. A., K. Kimura, H. M. Kubisch, and R. M. Roberts. 2001. Sexual dimorphism among bovine embryos in their ability to make the transition to expanded blastocyst and in the expression of the signalling molecule IFN-tau. Proc. Natl. Acad. Sci. USA 98:9677-9682

Lerchl, A. 1998. Seasonality of sex ratio in Germany. Hum. Reprod. 13:1401-1402.

Lyster, W. R. 1972. The sex ratios of human and sheep births in areas of high mineralization. Int. J. Environ. Stud. 2:309-316.

Macdonald, K. 1997. Lessons from Ruakura No. 2 dairy. Pages 4449 in Profitable Dairying. K. Macdonald, ed. NZ Rural Press, Auckland, NZ.

Macdonald, K. A., and J. R. Roche. 2004. Condition scoring made easy. Condition scoring dairy herds. 1st ed. Dexcel Ltd., Hamilton, New Zealand.

Macmillan, K. M., and R. J. Curnow. 1976. Aspects of reproduction in New Zealand dairy herds. 1. Gestation length. N.Z. Vet. J. 24:243-252.

Manning, J. T., R. H. Anderton, and M. Shutt. 1997. Parental age gap skews child sex ratio. Nature 389:344.

Pratt, N. C., U. W. Huck, and R. D. Lisk. 1987. Offspring sex ratio in hamsters is correlated with vaginal $\mathrm{pH}$ at certain times of mating. Behav. Neural Biol. 48:310-316.

Ray, P. F., J. Conaghan, R. M. L. Winston, and A. H. Handyside. 1995. Increased number of cells and metabolic activity in male human preimplantation embryos following in vitro fertilization. J. Reprod. Fertil. 104:165-171.

Reist, M., D. Erdin, D. von Euw, K. Tschuemperlin, H. Leuenberger, Y. Chilliard, H. M. Hammon, C. Morel, C. Philipona, Y. Zbinden, N. Kuenzi, and J. W. Blum. 2002. Estimation of energy balance at the individual and herd level using blood and milk traits in high-yielding dairy cows. J. Dairy Sci. 85:3314-3327.

Roche, J. R., P. G. Dillon, C. R. Stockdale, L. H. Baumgard, and M. J. VanBaale. 2004. Relationships among international body condition scoring systems. J. Dairy Sci. 87:3076-3079.

Roche, J. R., E. S. Kolver, and J. K. Kay. 2005. Influence of precalving feed allowance on periparturient metabolic and hormonal responses and milk production in grazing dairy cows. J. Dairy Sci. 88:677-689.

SAS Institute. 2005. User's Guide. Version 9.1: Statistics. SAS Institute, Cary, NC.

Sheldon, B. C., and S. A. West. 2004. Maternal dominance, maternal condition, and offspring sex-ratio in ungulate mammals. Am. Nat. 163:40-54.

Skjervold, H., and J. W. James. 1979. Causes of variation in the sex ratio in dairy cattle. Z. Tierz. Zuchtungsbio. 95:293-305.

Stolkowski, J., and J. Choukroun. 1981. Preconception selection in man. Isr. J. Med. Sci. 17:1061-1067.

Trivers, R. L., and D. Willard. 1973. Natural selection of parental ability to vary the sex ratio of offspring. Science 179:90-92.

Wildman, E. E., G. M. Jones, P. E. Wagner, R. L. Boman, H. F. Troutt, Jr., and T. N. Lesch. 1982. A dairy cow body condition scoring system and its relationship to selected production characteristics. J. Dairy Sci. 65:495-501.

Williams, R. J., and S. P. Gloster. 1992. Human sex ratio as it relates to caloric availability. Soc. Biol. 39:285-291. 